\title{
Use of a Suction drain in Thyroid Surgery
}

\author{
Wijesinghe K.M.G.S.S.S., Perera D.S.C, Mahathanthila D.M.K, \\ Pallewatta A.S, Jayasuriya C. \\ National Hospital of Sri Lanka.
}

\begin{abstract}
\section{Introduction}

The use of a suction drain in Thyroid surgery is in common practice. This is done mainly to 'prevent' formation of haematomas and seromas on the Thyroid bed and subsequently to reduce complications and hospital stay.
\end{abstract}

\section{Objective}

The aim of this study is to determine the efficacy of routine drainage after Thyroid surgery.

\section{Method}

A randomized prospective control trial was conducted on 50 patients over a period of ten months. These patients were randomly allocated to drained and non-drained groups. The surgeon was informed of the group just before the closure of the wound. Post-operative ultrasound scan neck was done on second post-operative day by the Radiologist to assess the amount of fluid on the thyroid bed. Wound infection, seroma and heamatoma formation were assessed during the hospital stay and $1^{\text {st }}$ and $2^{\text {nd }}$ week after surgery. Post-operative pain was also assessed on postoperative day 2. The data were analysed using two sample T-test.

\section{Results}

Both groups were homogenous according to the age, size of the gland, type of the procedure performed and histopathological diagnosis. There was no significant collection of fluid on the Thyroid bed assessed by the USS scan on day 2 in the 2 groups $(P=0.1016)$. But the length of hospital stay was significantly reduced amongst the non-drainedgroup ( $\mathrm{P}=0.0002)$. None of the patients in either group had post-operativeseroma orheamatomaand did not require reoperation for post-operative bleeding. No significant difference in post-operative pain was observed amongst two groups $(\mathrm{P}=0.6818)$.

\section{Conclusion}

Routine insertion of suction drain following Thyroid surgery is not necessary. Not applying a drain to the wound, resulted in decreased hospital stay. Post-operative pain is not increased significantly by inserting a drain.

\section{Introduction.}

The use of a suction drain in Thyroid surgery is in common practice. This is done mainly to 'prevent' formation of haematomas and seromas on the Thyroid bed and subsequently to reduce complications and hospital stay. Available data suggest that drain insertion has no significant effect on preventing these complications thus continued use of drains may be based on tradition rather than proven scientific evidence

\section{Material and Methods.}

Approval was taken from the board of study in Otorhinolaryngology and the ethical clearance committee of the National Hospital of Sri Lanka (NHSL) before initiating the study. The study was carried out on 50 patients who underwent thyroidectomies between January 2014 and October 2014 at the ENT unit of NHSL.

Patients who attended the ENT clinic during the study period were assessed. Those with thyroid disease requiring surgical intervention were briefed about the study. Patients who expressed interest in participating were given more information about the study and writteninformed consent was obtained. The patients were then divided randomly into two groups, group 1 'with drains' and group 2 'without drains'. 
Patients with a goiter who had a history of bleeding tendency, recurrent goiter, toxic goiter, thyroid cancer \& uncontrolled comorbidities such as Diabetes and Hypertension were excluded from the study. Computer based random number generation was used to divide the patients into 2 groups.

Patients were operated by the consultant ENT surgeon and senior registrar of the relevant unit. All relevant information obtained from the patient from the time of recruitment to discharge were recorded in a data collection form. Patients were examined sonographically 48 hours after surgery by the senior registrar in radiology under supervision of consultant Radiologist to estimate post op fluid collection on the thyroid bed. A visual analog score with scores ranging from 0 to 10 was used for pain assessment.Other complications including heamatoma\&seroma formation and wound infection were recorded.A standard patient care routine including 'discharge protocol' was followed. Patients were further followed up at the clinic at 1week and 2weeks post operatively to monitor for complications and totrace the histology.

Data such as age and duration of hospital stay were analyzed using the student T-Test. Difference in the pain scores were analyzed using Mann-Whiney U test.

\section{Results.}

We performed 50 Thyroidectomies between January 2014 and October 2014.Average age of patients in the study was 43.3 years. (Range from 68 to 21). Male female ratio was1:6.28. There was equal distribution in both groups based on type of surgery and size of the nodule.

\begin{tabular}{|l|c|c|}
\hline & Drain group & $\begin{array}{c}\text { Non drain } \\
\text { group }\end{array}$ \\
\hline Age & 44.28 & 42.32 \\
\hline Gender & $4 / 21$ & $3 / 22$ \\
\hline $\begin{array}{l}\text { Type of Surgery- } \\
\text { Hemi-Thyroidec- } \\
\text { tomy/Total Thy- } \\
\text { roidectomy }\end{array}$ & $19 / 6$ & $18 / 7$ \\
\hline Diagnosis Benign & 23 & 22 \\
\hline Malignant & 2 & 3 \\
\hline
\end{tabular}

Table 1 -Patient Characteristics

The amount of fluid collected in the Thyroid bed as assed by Ultrasound scan (USS) for both groups on day two is shown table 2. A two sample T-test was applied and it showed no statistically significant difference in the volume of fluid collection on day two $(p=0.1016)$ between two groups. Average collection of fluid in the suction drain in 48 hours is $48.7 \mathrm{ml}$ (range 20 to $70 \mathrm{ml}$ )

\begin{tabular}{|c|c|c|}
\hline Amount of fluid & Drain group & $\begin{array}{c}\text { Non drain } \\
\text { group }\end{array}$ \\
\hline Mean & $0.87516 \mathrm{ml}$ & $1.53040 \mathrm{ml}$ \\
\hline Minimum & $0.1 \mathrm{ml}$ & $0.1 \mathrm{ml}$ \\
\hline Maximum & $3.5 \mathrm{ml}$ & $7.9 \mathrm{ml}$ \\
\hline Total no of patients & 25 & 25 \\
\hline
\end{tabular}

Table 2 - Volume of fluid collected in the two groups as assessed by USS on D2

\begin{tabular}{|c|c|c|c|}
\hline & $\mathrm{T}$ & DF & Probability (P) \\
\hline D2 & 1.6691 & 48 & 0.1016 \\
\hline
\end{tabular}

Two sample t test for detection of difference in means of fluid collection on D2

The average duration of hospital stay was 3.12 
days for the drain group and 2.04 days for the non-drain group. This was statistically significant when analyzed using two sample test $(\mathrm{p}=0.0002)$

\begin{tabular}{|c|c|c|}
\hline & $\begin{array}{c}\text { Drain } \\
\text { group }\end{array}$ & $\begin{array}{c}\text { Non drain } \\
\text { group }\end{array}$ \\
\hline Mean & 3.12 & 2.04 \\
\hline Minimum days of stay & 2 & 1 \\
\hline Maximum days of stay & 5 & 4 \\
\hline Total no of patients & 25 & 25 \\
\hline
\end{tabular}

Table 3 - Duration of Hospital Stay

\begin{tabular}{|c|c|c|}
\hline $\mathrm{T}$ & $\mathrm{DF}$ & $\mathrm{P}$ \\
\hline 4.1016 & 48 & 0.0002 \\
\hline
\end{tabular}

No significant difference in post-operative pain was observed in both groups on postoperative day 2. (Table 4)

\begin{tabular}{|c|c|c|c|}
\hline & Drain group & \begin{tabular}{|l|}
$\begin{array}{l}\text { Non Drain } \\
\text { group }\end{array}$ \\
\end{tabular} & P Value \\
\hline $\begin{array}{ll}\text { Mean } & \text { VAS } \\
\text { Score } & \end{array}$ & $4.25(2-6)$ & $3.04(2-5)$ & 0.6818 \\
\hline
\end{tabular}

Table 4 - Mann-Whitney U test used for the assessment

None of the patients in either group had postoperative complications such as seroma or hematoma and did not require reoperation for post-operative bleeding.

\section{Discussion.}

Numerous studies have failed to show any benefit of drains in thyroid surgery. Results of our study is similar to this and post-operative USS shows similar collections on thyroid bed in drain and non-drain groups.

The drain group still had high volumes of fluid in drains indicating that presence of suction drains may inducemore drainage due tonegativepressure and local inflammation caused by presence of the drain. Many surgeons believe use of drains following thyroid surgery is to 'obliterate' the dead space and to evacuate collected blood and serum. This is further reinforced by the fact that postoperative drains usually yield fluid.

Haemorrhage can be a life threatening complication that would necessitate immediate reoperation. This fear prompts surgeons to use routine drains after thyroid surgery. Post-operative bleeding is actually quite rare and occurs only in $0.3 \%$ to $1 \%$ of patients after thyroidectomy ${ }^{1,2}$ Many studies have suggested that drains may be blocked with clotted blood and the surgeon may not be alerted even if major bleeding occurs. In our study we did not encounter any patient with post-operative bleeding and therefore are unable to comment on this.

In one study seung et al found that the time to discharge after thyroid surgery was significantly shortened in the 'no drain' group compared to 'drain' group 4 . We had a similar result as the hospital stay is significantly reduced in our'nondrain' group as well. Hyoung et al reported the incidence of haematoma formation post Thyroidectomy to be varying between $0.3 \%$ $-4.3 \%{ }^{3}$.We did not have any haematoma or seroma formation in our study

\section{Conclusion}

Our randomized control study shows that routine drain placement after uncomplicated thyroid surgery is not necessary and not effective in decreasing post-operative complications. Meticulous haemostasis during surgery is more important in achieving this goal.

Thyroid surgery without drains decrease the length of hospital stay. Post-operative pain is not significantly increase due to insertion of drain.

\section{Key Messages.}

Routine insertion of a suction drain following Thyroid surgery is not necessary. Not applying a drain to the wound, resulted in decreased hospital stay. Post-operative pain is not increased significantly by inserting a drain. 


\section{References.}

1. Colak,T.,Akca,T.,Turkmenoglu et al.," Drainage after total Thyroidectomy or Lobectomy for benign thyroid disorders", Journal of Zheijong Universityscience B,vol 9,no4,pp 319 - 323,2008

2. Bergqvist,D., Kallero,S.," Reoperation of Postoperative HeamorragicComplications, analysis of 10 year series,vol 151,no 1,pp 17 - 221985

3. Hyoug,S.L., Sung,W.K.,Young, W.,C.,YoHan, P.,Kang, D.L.,Patterns of post thyroidectomy heamorrage.Clinical\&experimental Otorhinolaryngology.2009;pp 72 - 79

4. Seung, W.L.,Eun, C.I.,Young, M.L.,Jae, Y.L.,Shi, C.K.,Yoon woo koh., "Islack of placement of drains after thyroidectomy safe?", The American laryngological rhinological and ontological society,Inc;2006

5. Salsu N,Vural S,Oncel M,et al; "Is the insertion of drains after uncomplicated Thyroid surgery always necessary?"Surg Today 2006;36(3)215 - 8
6. Morrissey, A.T.,Chau, J.,Yunker, W.K.et al, "comparison of drain verses no drain Thyroidectomy randomized prospective control trial”. J Otolaryngology Head \& Neck Surg 2008 Feb;37(1):43 - 7

7. Shaha, A.R.,Jaffe, B.M., "Selective use of drains in Thyroid Surgery" J Surg Oncol 1993Apr;52(4):241 - 3

8. Samraj, K.,Gurosamy, K.S., "wound drains following Thyroid surgery" Cochrane Database Syst Rev 2007 Oct 17;(4):CD006099

9. Musa, A.A.,Agbock, O.J.,Banjo, A.A.,Oyegunle, O., "The use of drains in Thyroid Surgery", Niger Postgrad Med J.2010 Mar;17(1):15 - 17 